\title{
TECENDO A REDE: O DESAFIO DO EMPODERAMENTO DE USUÁRIOS E FAMILIARES NA REDE DE ATENÇÃO PSICOSSOCIAL, EM CRICIÚMA (SC)
}

\begin{abstract}
Priscila Schacht Cardozo
Mestranda em Saúde Coletiva, Universidade do Extremo Sul Catarinense,

prish_cardozo@hotmail.com

Ivan de Souza Ribeiro

Especialista em História Social e Cultural, Universidade do Extremo Sul Catarinense, isribeir@hotmail.com

Dipaula Minotto da Silva

Mestranda em Saúde Coletiva, Universidade do Extremo Sul Catarinense, dipaulaminotto@yahoo.com.br João André Rodrigues

Especialista em Educação Permanente em Saúde, Escola Nacional de Saúde Pública, joaoandrerodrigues@live.com
\end{abstract}

\section{RESUMO}

A entidade Anarquistas Contra o Racismo (ACR) atua na cidade de Criciúma e regiấo desde 1997, desenvolvendo projetos nas temáticas de Direitos Humanos. Atualmente, organiza-se por núcleos, os quais são: Núcleo da Diversidade Sexual, Núcleo de Educação e Negritude, Núcleo Anarcopunk e Núcleo de Saúde Mental. Todas as ações da ACR vêm ao encontro das diretrizes e discussões sobre direitos humanos no cenário nacional e com as políticas públicas de saúde mental, contribuindo para a construção de uma sociedade sem manicômios, no 
sentido mais amplo deste conceito. Observa-se que o contexto histórico e geográfico de Criciúma, de uma lógica hospitalocêntrica, pois sedia um Hospital Psiquiátrico Regional, sofre forte influência na forma como o processo saúde/ doença mental é compreendido e cuidado. Atualmente, a rede de saúde mental, apesar de ser a segunda maior de Santa Catarina, sendo a primeira em Joinville, ainda não é compreendida pela sociedade e pelos movimentos sociais como rede de serviços substitutivos ao Hospital Psiquiátrico. A criação do Núcleo de Saúde Mental da ACR nasce a partir do encontro de militantes do Movimento de Luta Antimanicomial, ex-trabalhadores da Rede de Atenção Psicossocial (RAPS) do município e parceiros, com o objetivo de articular novos espaços de discussão, reflexão e promoção de saúde mental. Em 2013, este núcleo propôs a elaboração do projeto intitulado "Tecendo a Rede: o Desafio do Empoderamento de Usuários e de Familiares e a Contribuição para o Processo de Desinstitucionalização e Acolhimento na RAPS - Rede de Atenção Psicossocial em Criciúma (SC)" à Coordenação Municipal de Saúde Mental e à Secretaria Municipal de Saúde de Criciúma. Após o aceite, o projeto foi enviado para o processo seletivo do "Edital de II Chamada de Projetos de Fortalecimento do Protagonismo de Usuários e Familiares da RAPS”, da Coordenação Nacional de Saúde Mental, Álcool e Outras Drogas, do Ministério da Saúde, sendo este aprovado em novembro do mesmo ano. O objetivo geral do projeto foi estimular o protagonismo dos usuários dos serviços de saúde mental e de seus familiares, visando fortalecer o processo de desinstitucionalização e acolhimento na RAPS em Criciúma (SC). Todas as atividades do projeto foram construídas a partir da perspectiva de trabalho interdisciplinar (psicólogos, assistente social, historiador), no formato horizontal e assembleísta, com reunióes semanais de planejamento e de avaliação das atividades desenvolvidas. O projeto foi executado no período de junho a dezembro de 2014, iniciando suas atividades com a apresentação da proposta de atuação ao Conselho Municipal de Saúde e, posteriormente, aos coordenadores dos CAPS II, CAPS ad, CAPS I e CAPS III, e, em seguida, à Associação de Usuários, Familiares e Amigos da Saúde Mental de Criciúma. Após a socialização com todos os envolvidos, desenvolvemos 22 oficinas de Direitos Humanos, sendo oito no CAPS I, seis no CAPS III e oito no CAPS ad, que incluíram usuários, familia- 
res e profissionais. Os temas abordados foram: “O que é Direito Humano?”, "Preconceito e discriminação", "Participação e controle social", "Histórico da luta antimanicomial e da reforma psiquiátrica", "Cidadania" e "RAPS". Como fechamento das oficinas, realizamos uma oficina de scrapbooking, com a proposta de expressão artística e avaliação do processo com os envolvidos. A metodologia de trabalho com o público-alvo foi baseada na proposta de educação popular em saúde, norteada pelos princípios da pedagogia de Paulo Freire (2002), com exposiçóes dialogadas, como vídeo-debate, rodas de conversa, dinâmicas de grupo e disponibilização de materiais informativos, priorizando o debate reflexivo dos participantes das oficinas. Como ferramenta de avaliação e monitoramento, ao término de cada encontro, os técnicos do projeto elaboraram memorial descritivo, registro fotográfico e lista de presença dos participantes. Também como atividade do projeto, realizamos um vídeo debate/roda de conversa com os profissionais da RAPS do município, com o tema "A importância da rede intersetorial no processo de desinstitucionalização em saúde mental”, mediado pela psicóloga Sandra Vitorino, Coordenadora de Saúde Mental de Joinville. Por fim, houve registro para uma mostra fotográfica e realização de vídeo de curta metragem da experiência das pessoas nas oficinas, a fim de capturar, por meio das imagens, um pouco da realidade do cotidiano do serviço, bem como do caminhar do projeto. O vídeo foi apresentado no evento de encerramento do projeto. Percebemos que o projeto "Tecendo a Rede" permitiu uma importante mobilização no cenário da rede de atenção em saúde mental, possibilitando a inserção do núcleo de saúde mental da ACR como integrante da RAPS, contribuindo, assim, no processo de desinstitucionalização e fortalecendo a articulação da rede de saúde mental, com foco no protagonismo de usuários e familiares. Este diálogo com a rede se mostrou mais sólido durante a realização das oficinas, quando convivências dentro dos CAPS favoreceram novos olhares por parte dos profissionais, ao mesmo tempo em que apresentou ao núcleo uma melhor compreensão de como a rede de saúde mental de Criciúma vem se reconhecendo e "tecendo". O contato com os usuários e familiares foi de grande valor neste processo. No diálogo com estes atores, verificamos que seus papéis ainda são de atores passivos na construção cotidiana dos serviços e da rede. O protagonismo de usuários e familiares, foco des- 
te projeto, tornou-se objeto a ser explorado. Os profissionais que participaram das oficinas expressaram surpresa e satisfação com a proposta. O projeto estimulou reflexóes sobre a desmistificação do protagonismo enquanto gerador de conflitos, ao mesmo tempo em que se apresentou como ato promotor de cidadania e de reabilitaçáo psicossocial. O principal ganho do projeto foi o interesse e a disponibilidade dos usuários, familiares e profissionais com as temáticas discutidas. Se, em um primeiro momento, houve curiosidade e expectativa, no decorrer houve ricas reflexôes e construçóes coletivas sobre Direitos Humanos e Saúde Mental, além das inquietaçóes, questionamento e olhares curiosos, ou seja, houve um espaço destinado a dar voz às questóes relacionadas a cada um dos temas. Tivemos relatos impactantes sobre violaçôes de direitos, bem como relatos de desconhecimento da RAPS enquanto política de atenção em saúde mental. Verificamos sentimentos de discriminação e preconceitos, decorrentes do sofrimento psíquico, entre outras falas nesta perspectiva. A conduta do núcleo se deu em promover uma escuta acolhedora, aliada a orientaçóes e informaçóes pertinentes, focando a (re)construção da cidadania, entendendo que a busca por direitos e a compreensão do seu papel social são em si propostas de reabilitação psicossocial. Ao considerar as demandas, apresentamos, em nova edição do mesmo Edital do MS, ao final de 2015, o "Projeto Tecendo a Rede II", com foco na construção de um fórum de atenção psicossocial e organização de um grupo de estudos sobre Direitos Humanos e Saúde Mental, bem como a capacitação de usuários para a formação de grupos de ajuda e suporte mútuo (VASCONCELOS, 2003), a ser executado em 2016.

Palavras-chave: Saúde Mental; Desinstitucionalização; Direitos Humanos.

\section{INSTITUIÇÃO FINANCIADORA}

Ministério da Saúde - Coordenação Nacional de Saúde Mental, Álcool e Outras Drogas. 


\section{AGRADECIMENTOS}

Agradecemos aos usuários, familiares e profissionais que enriqueceram os encontros nas oficinas de Direitos Humanos. Agradecemos também às Coordenaçóes Nacional e Municipal de Saúde Mental e à Secretaria Municipal de Saúde de Criciúma, que apostaram junto com ACR neste projeto. Ao militante mineiro Marcus Vinícius de Oliveira (Matraga - in memorian) e ao usuário criciumense Jamir dos Santos Cruz, (in memorian) pela inspiração.

\section{REFERÊNCIAS}

FREIRE, P. Pedagogia da autonomia: saberes necessários à prática educativa. 21. ed. Rio de Janeiro: Paz e Terra, 2002.

VASCONCELOS, E. M. Ajuda e suporte mútuos em saúde mental: para facilitadores, trabalhadores e profissionais de saúde e saúde mental. Rio de janeiro: UFRJ, 2003. 